\title{
Biotechnologies for Metal Extraction: Assessment of Microalgae for Rare Earths Recycling and Environmental Remediation
}

\author{
Pro Danièle ${ }^{1}$, Vial Jérôme ${ }^{2}$, Rivasseau Corinne ${ }^{1}$ \\ ${ }^{1}$ Commissariat à l'Energie Atomique et aux Energies Alternatives \\ 17 rue des Martyrs, Grenoble, France \\ Corinne.rivasseau@cea.fr; dr.danielepro@gmail.com \\ ${ }^{2}$ Laboratoire Sciences Analytiques, Bioanalytiques et Miniaturisation ESPCI-ParisTech \\ 10 rue Vauquelin, Paris, France \\ Jerome.vial@espci.fr
}

\section{Extended Abstract}

The rare earths elements are metallic elements of strategic importance due to their multiple applications in high technologies, electronics, green energy, the automobile industry, the defense industry, etc. They take an essential part in permanent magnets, rechargeable batteries, lamp phosphors, catalysts, or hard disk drivers. They have been increasingly used in the last years, with an annual rise in the demand reaching $30 \%$ for some of them. Only one country, China, ensures over $90 \%$ of the world supply. In the early $2010^{\text {ies }}$, China strongly reduced its export quotas for rare earths, leading to a drastic increase in prices, damaging industries in other countries, and forcing producers of rare earth products to relocate their operations to China. Facing the increasing use of rare earths and their uncertain supply, developed countries have developed new strategies to ensure access to these critical materials, including their recycling from electronic waste, used fluorescent lamps, magnets, and batteries, as an example [1,2]. Rare earths are conventionally extracted by pyrometallurgy and hydrometallurgy, which are mainly used at present despite their cost in energy and chemicals. In many fields, more environmentally friendly biotechnological processes have proved their efficiency. In recent years, several studies have shown the potential of biotechnologies for the recovery of rare earths [3].

Over the past few years, we have been studying the properties of microalgae of the Coccomyxa genus which were isolated from an extreme environment [4]. These microalgae withstand radiative, nutrient and metallic stress [5] and also have non-selective metal uptake properties. This makes them organisms of choice for the development of bioprocesses for rare earth extraction from matrices presently considered as waste for their recycling as well as from contaminated environments for remediation purposes.

This work assesses the potential of these microalgae for such processes. By using an experimental design, the impact of various parameters on metal uptake was studied, including the nature of the rare earth element, its initial concentration, its speciation, the exposure $\mathrm{pH}$ and the contact time. This original approach enables to assess a large panel of conditions while minimizing the number of experiments. Two types of responses were analyzed: the physiological state of microalgae during exposure and responses regarding the accumulation of the rare earth. The percentage of purification was analyzed for remediation purposes, and the amount of metal accumulated for recycling. This study highlighted operating conditions for which the percentage of rare earth decontamination and the rare earth amount accumulated by microalgae were maximized. Accumulation was compared for the different elements tested. More than $90 \%$ of the metal could be removed from water within a few hours, with a concentration factor of about 20,000 [6]. Up to $15 \mathrm{mg}$ of rare earth/g dry weight could be taken up by microalgae. Studies relating the take up of rare earths by microalgae are not numerous, but the fixation capacity determined in this work was superior to the amount reported for another algal species [7]. This work demonstrated the potential of these microalgae for environmental remediation of rare earths and for their recycling from urban mining.

\section{References}

[1] K. Binnemans, P. T. Jones, B. Blanpain, T. V. Gerven, Y. Yang, A. Walton and M. Buchert, "Recycling of rare earths - a critical review," J. Clean. Product., vol. 51, pp. 1-22, 2013. 
[2] Z. Sun, Y. Xiao, H. Agterhuis, J. Sietsma, Y. Yang, "Recycling of metals from urban mines e a strategic evaluation," J. Clean. Product., vol. 112, pp. 2977-2987, 2016.

[3] T. Tsuruta, "Accumulation of Rare Earth Elements in Various Microorganisms," J. Rare Earths, vol. 25, no. 5, pp. 526-532, 2007.

[4] C. Rivasseau, E. Farhi, A. Atteia, A. Couté, M. Gromova, D. de Gouvion Saint Cyr, A.-M. Boisson, A.-S. Féret and R. Bligny, "An extremely radioresistant green eukaryote for radionuclide bio-decontamination in the nuclear industry," Energy Environ. Sci., vol. 6, no. 4, pp. 1230-1239, 2013.

[5] T. Leonardo, E. Farhi, S. Pouget, S. Motellier, A. M. Boisson, D. Banerjee, F. Rébeillé, C. Den Auwer and C. Rivasseau, "Silver Accumulation in the Green Microalga Coccomyxa actinabiotis: Toxicity, in Situ Speciation, and Localization Investigated Using Synchrotron XAS, XRD, and TEM," Environ. Sci. Technol., vol. 50, no. 1, pp. 359367, 2016.

[6] C. Rivasseau, E. Farhi, A. Atteia and D. Pro, "A new microalga of the Coccomyxa genus," WO 2014, pp. 174483, 2014.

[7] H. Sun, X.-R. Wang and L.-S. Wang, "Bioconcentration of rare earth elements Lanthanum, Gadolinium and Yttrium in algae Chlorella vulgaris Beijerinck: influence of chemical species," Chemosphere, vol. 34, no. 8, pp. 1753-1760, 1997. 